\title{
EFFECTIVE AND RELIABLE METHOD FOR EXTRACTIONS OF ANTHRACENE
}

\author{
A. N. Z. Abidin ${ }^{1}$, S. A. Talib ${ }^{2}$, S. Alias ${ }^{3}$ and C. C. Tay ${ }^{1,2, *}$ \\ ${ }^{1}$ Faculty of Applied Science, UniversitiTeknologi MARA, 40450 Shah Alam, Selangor, \\ Malaysia \\ ${ }^{2}$ Faculty of Civil Engineering, UniversitiTeknologi MARA, 40450 Shah Alam, Selangor, \\ Malaysia \\ ${ }^{3}$ Faculty of Civil Engineering, UniversitiTeknologi MARA, 13500 Permatang Pauh, Pulau \\ Pinang, Malaysia
}

Published online: 17 October 2017

\begin{abstract}
Anthracene often used as model compound for degradation study, especially for high molecular weight PAHs. Hence, efficient extraction of anthracene is vital forGC-MS analysis. This study focuses on the efficiency of extraction methods between Solid Phase Extraction (SPE) and liquid-liquid extraction (LLE). The study was also conducted to assess the effect of sonication during extraction process. LLE showed a higher recovery at $96.65 \%$ compared to $\mathrm{SPE}$ at $46.22 \%$. For extraction method development in minimal salt solution, sonication prior to sample withdrawal showed the highest recovery at $94.25 \%$ compared to mechanical shaking at $73.67 \%$ and sonication extraction at $65.06 \%$.Hence, this study exhibits a reliable and effective technique on anthracene extraction prior to GC-MS analysis. It is important for anthracene determination using GC-MS in further degradation study.
\end{abstract}

Keywords: Anthracene; extraction; LLE; sonication; SPE.

Author Correspondence, e-mail: taychiay@gmail.com

doi: http://dx.doi.org/10.4314/jfas.v9i5s.49 


\section{INTRODUCTION}

\subsection{Occurrence and Degradation of Anthracene}

Polycyclic Aromatic Hydrocarbons (PAHs) are fused benzene rings arranged in linear, angular or clustered manner that are hydrophobic and has high persistency in the environment [1]. Most PAHs are mutagenic, toxigenic, genotoxic and carcinogenic[2].Anthracene is a three-ring PAHarranged in a linear manner.When it enters the body, it attacksthe skin, stomach, intestines, lymphatic system and hematopoietic system[3-4]. Anthracene is exacerbated by anthropogenic activities and is found prevalent in soil, sediment and surface water [5-6]. It is one of the 16 PAHs listed in USEPA[7].

Due to its structure that is found in high molecular weight PAHs such as benzo(a)pyrene, benzo(a)anthracene or tetracene, anthracene is always used as a model PAH in degradation study [8]. For this reason, it is crucial to establish the effectiveand reliable method of extraction and analysis to ensure the validity of result as well as repeatability and reproducibility of study.

There were several studies established using various extraction methods specifically for PAHs. For example, there are Soxhlet extraction, sonication, liquid-liquid extraction (LLE), pressurized fluid extraction (PFE), supercritical and subcritical fluid extraction (SFE), microwave-assisted extraction (MAE), solid phase extraction (SPE) and solid phase micro-extraction (SPME) [9]. Soxhlet extraction is the most commonly used extraction method due to high recovery. However, the method uses a lot of solvents and time-consuming. There is also the possibility of targeted compound degradation during sonication. PFE is more suitable for solid matrix sample while SFE requires a highly advanced instrument setup. MAE is unsuitable for low molecular weight PAHs due to volatility of PAHs at high temperature [9].Therefore, LLE, SPE and SPME are viable techniques for extraction for low molecular weight PAHs. Due to high cost incurred for SPME method, as a result, this study focuses on LLE and SPE methods for anthracene extraction. For extraction method optimization, volume of solvent use, types of solvent use and amount of sample are investigated [9]. To authors' best knowledge, there is lack of study on effect of sonication during extraction process. Such approach may increase extraction percentage and reduce work load on extraction.

This study focuses on method comparison between extraction using LLE (mechanical 
agitation) and SPE. Method development on effect of sonication during extraction processwas also evaluated.

\section{METHODOLOGY}

\subsection{Chemicals}

The analytical standard of anthracene was purchased from Merck, Germany (purity $>99 \%$ ). Methanol and acetonitrile HPLC grade was purchased from Friendemann and Schmidt Chemical and Fisher Chemical respectively. A 2.0 g of $\mathrm{Na}_{2} \mathrm{HPO}_{4}, 0.71 \mathrm{~g}$ of $\mathrm{K}_{2} \mathrm{SO}_{4}, 4.0 \mathrm{~g}$ of $\mathrm{NH}_{4} \mathrm{HPO}_{4}, 0.53 \mathrm{~g}$ of $\mathrm{KH}_{2} \mathrm{PO}_{4}$ and $0.10 \mathrm{~g}$ of $\mathrm{MgSO}_{4} \cdot 7 \mathrm{H}_{2} \mathrm{O}$ was used for Minimal Salt Solution (MSS) preparation in $1000 \mathrm{ml}$ of Ultra Pure Water (ELGA, PureLab Ultra).

\subsection{Chromatographic Condition}

Gas chromatography was performed using Clarus 600 (Perkin Elmer ${ }^{\mathrm{TM}}$ ) with Mass Spectrometer Clarus $600 \mathrm{C}$ as the detector (Perkin Elmer ${ }^{\mathrm{TM}}$ ). Chromatographic separation technique was performed using capillary column Elite $5 \mathrm{~ms}$ (Perkin Elmer $^{\mathrm{TM}}$ ). The initial oven temperature for the analysis is $50^{\circ} \mathrm{C}$ for one minute with ramp at $11.8^{\circ} \mathrm{C}$ per minute to $250^{\circ} \mathrm{C}$ and hold for two minutes. Sampling rate was set at 12.5 points per second with an auto-injection volume of $1 \mu \mathrm{L}$.

\subsection{Sample Preparation and Calibration Curve}

A $100 \mathrm{mgL}^{-1}$ anthracene (Merck, Germany) standard solution was prepared by dissolving $0.005 \mathrm{~g}$ of anthracene in $50 \mathrm{~mL}$ methanol. A $20 \mathrm{mgL}^{-1}$ anthracene standard solution was prepared by diluting the prepared stock solution of $100 \mathrm{mgL}^{-1}$ anthracene standard solution. A $1.5 \mathrm{~mL}$ of $20 \mathrm{mgL}^{-1}$ anthracene solution was transferred into amber vial (Cronus ${ }^{\mathrm{TM}}$ ). The steps were replicated for $1 \mathrm{mgL}^{-1}, 2 \mathrm{mgL}^{-1}, 4 \mathrm{mgL}^{-1}, 6 \mathrm{mgL}^{-1}, 8 \mathrm{mgL}^{-1}$ and $10 \mathrm{mgL}^{-1}$ anthracene standard solutions.

Each anthracene standard solution in amber vials was analyzed using GC-MS. All standards were prepared in triplicates. The retention time of anthracene was identified. The graph response versus anthracene was plotted and evaluated. The limit of detection was calculated using the equation: $3.3 *$ s.d/slope [10].

\subsection{Extraction Method Analysis}

LLE and SPE method was applied in this study. For determination of efficient extraction 
method, the maximum value of anthracene extraction is chosen through recovery study (section 2.7).

\subsubsection{LLE Method}

Standard solution for anthracene at $10 \mathrm{mgL}^{-1}$ concentration was prepared by diluting 100 $\mathrm{mgL}^{-1}$ in MSS as mentioned in section 2.3. The $10 \mathrm{mgL}^{-1}$ concentration was selected for extraction study. LLE method was conducted to extract the samples. Each separatory funnel was washed using $5 \mathrm{~mL}$ of hexane, discarded and then with $5 \mathrm{~mL}$ acetone to remove traces of PAH. A $2 \mathrm{~mL}$ of the $10 \mathrm{mgL}^{-1}$ solution was transferred into the separatory funnel and followed by $11 \mathrm{~mL}$ methanol: $9 \mathrm{~mL}$ acetonitrile. The mixture was shaken vigorously for two minutes to increase contact time of anthracene and organic solvent. At the same time, pressure was released after shaking. The extracted samples were rotavaped (Buchi ${ }^{\mathrm{TM}}$ ) at 226 mbar to remove acetonitrile and analyzed using GC-MS at condition mentioned insection 2.2.

\subsubsection{SPE Method}

A $10 \mathrm{mgL}^{-1}$ solution for anthracene was prepared by diluting $100 \mathrm{mgL}^{-1}$ stock solutionin MSS as section 2.3. The standard solution duplicate samples were extracted using VisiPrep ${ }^{\text {TM }}$ SPE Vacuum Manifold Solid Phase Extraction (SPE) using specific cartridge for PAH analysis, Supelclean $^{\mathrm{TM}}$ ENVI $^{\mathrm{TM}}-18$ SPE 57064 cartridges (Supelco ${ }^{\mathrm{TM}}$ ). Each SPE cartridge was equilibrated using $2 \mathrm{~mL}$ methanol. A $2 \mathrm{~mL}$ of the $10 \mathrm{mgL}^{-1}$ standard solution was eluted into the cartridge followed by $11 \mathrm{~mL}$ methanol: $9 \mathrm{~mL}$ acetonitrile. The cartridge was dried under negative pressure using vacuum pump. The extracted samples were rotavaped (Buchi $\left.{ }^{\mathrm{TM}}\right)$ at 226 mbar to remove acetonitrile and analyzed using GC-MS using condition described in section 2.2.

\subsection{Sonication Effect onExtraction Method Development}

Method development on effect of sonication during extraction process is highlighted in this study. Comparison among sonication before sample withdrawal, sonication extraction and mechanical shaking during extraction were evaluated. The highest recovery study is selected as the most reliable and effective developed method.

\subsubsection{Method 1}

A $10 \mathrm{mgL}^{-1}$ of anthracene in MSS was prepared as section 2.3. Samples were agitated using sonicator prior to sample withdrawal for ten minutes. A $2 \mathrm{~mL}$ of the sample was withdrawn at 
the top and was extracted using the method mentioned in section 2.4LLE method.

\subsubsection{Method 2}

An amount of $10 \mathrm{mgL}^{-1}$ of anthracene in MSS was prepared as section 2.3. Samples were agitated using sonicator prior to sample withdrawal for ten minutes. Later, $2 \mathrm{~mL}$ of the sample was withdrawn at the top and was extracted using solvent ratio mentioned in section 2.4 LLE methodby using sonicator for two minutes. After sonication, the extracted samples were rotavaped (Buchi $\left.{ }^{\mathrm{TM}}\right)$ at 226 mbar to remove acetonitrile and analyzed using GC-MS using condition as in section 2.2 .

\subsubsection{Method 3}

A $10 \mathrm{mgL}^{-1}$ of anthracene in MSS was prepared as mentioned in section 2.3. Two minutes mechanical shaking was applied instead of sonication prior to sample withdrawal and extraction was continued as mentioned in section 2.4LLE method.

\subsection{Data Analysis for Recovery Study}

The response obtained from analysis of anthracene were recorded.The recovery percentage and average recovery percentage were calculated using Equation (1) and Equation (2) respectively.

$$
\begin{aligned}
& \text { Recovery percentage, } \%=\frac{\text { Response reading of extracted samples }}{\text { Response reading of control }} \times 100 \%(1) \\
& \text { Average recovery percentage, } \%=\frac{\text { Total recovery percentage }}{\text { Number of replicates }} \times 100 \%(2)
\end{aligned}
$$

The average recovery percentage was used to plot graph of average recovery percentage versus extraction methods. The result was also analyzed using one-way ANOVA analysis. To verify the one-way ANOVA, t-test was conducted.

\section{RESULTS AND DISCUSSION}

\subsection{Anthracene Retention Time}

Fig. 1 shows time profile for different anthracene concentrations. The retention time for anthracene at concentrations $1 \mathrm{mgL}^{-1}, 2 \mathrm{mgL}^{-1}, 4 \mathrm{mgL}^{-1}, 6 \mathrm{mgL}^{-1}, 8 \mathrm{mgL}^{-1}, 10 \mathrm{mgL}^{-1}$ and 20 $\mathrm{mgL}^{-1}$ wereranging from 14.83 to 14.91 minutes. The average retention time was found to be at 14.85 minutes. 

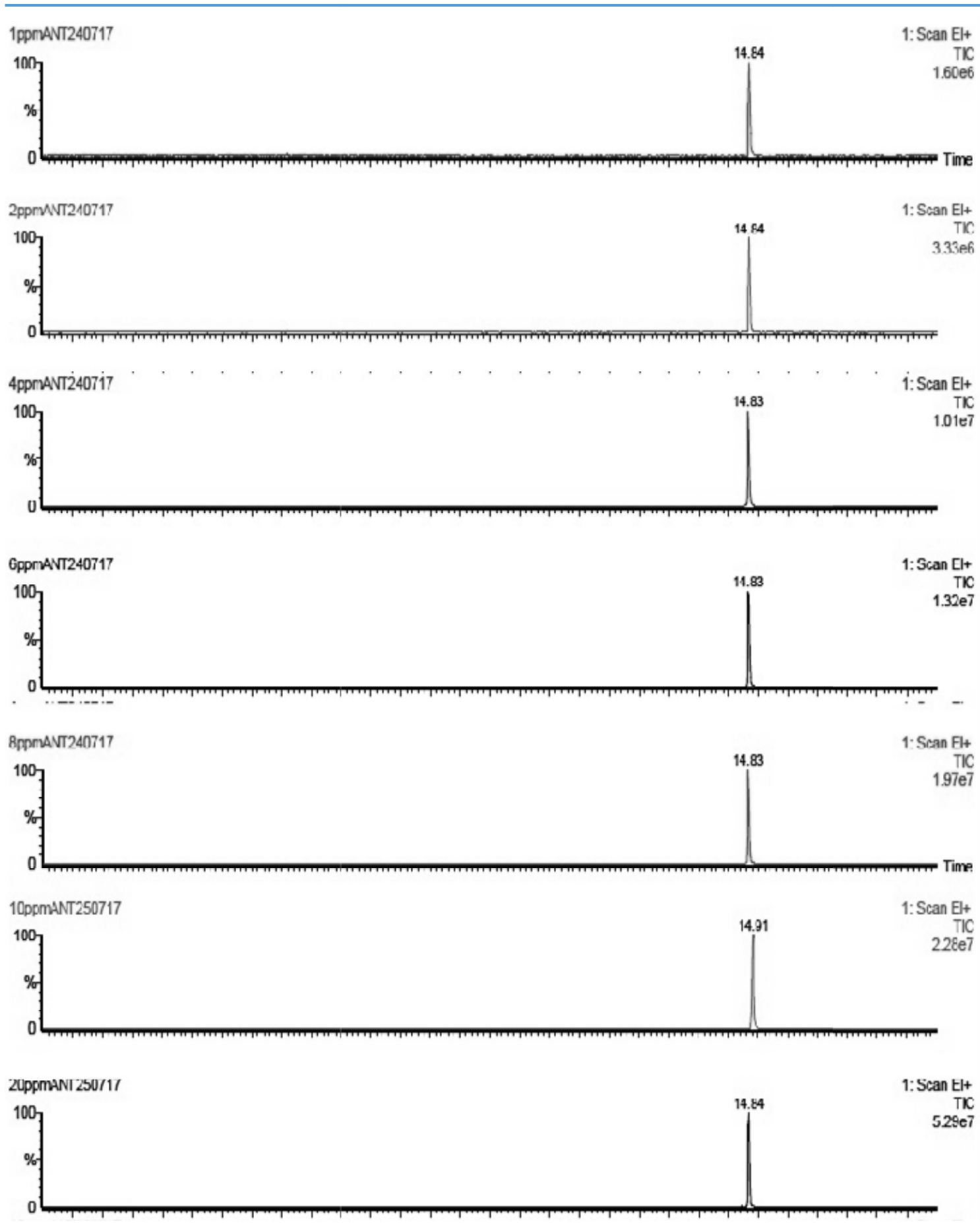

Fig.1.Anthracene time profile for different concentrations

\subsection{Anthracene Calibration Curve}

Fig. 2 illustrates calibration curve for anthracene. Equation of the graph was $y=2483.5 x$ and value for correlation coefficient $\left(\mathrm{R}^{2}\right)$ was 0.9956 . High $\mathrm{R}^{2}$ value represents excellent reliability and accuracy of the analysis. The detection limit was at $3.07515 \times 10^{-5} \mathrm{mgL}^{-1}$. 


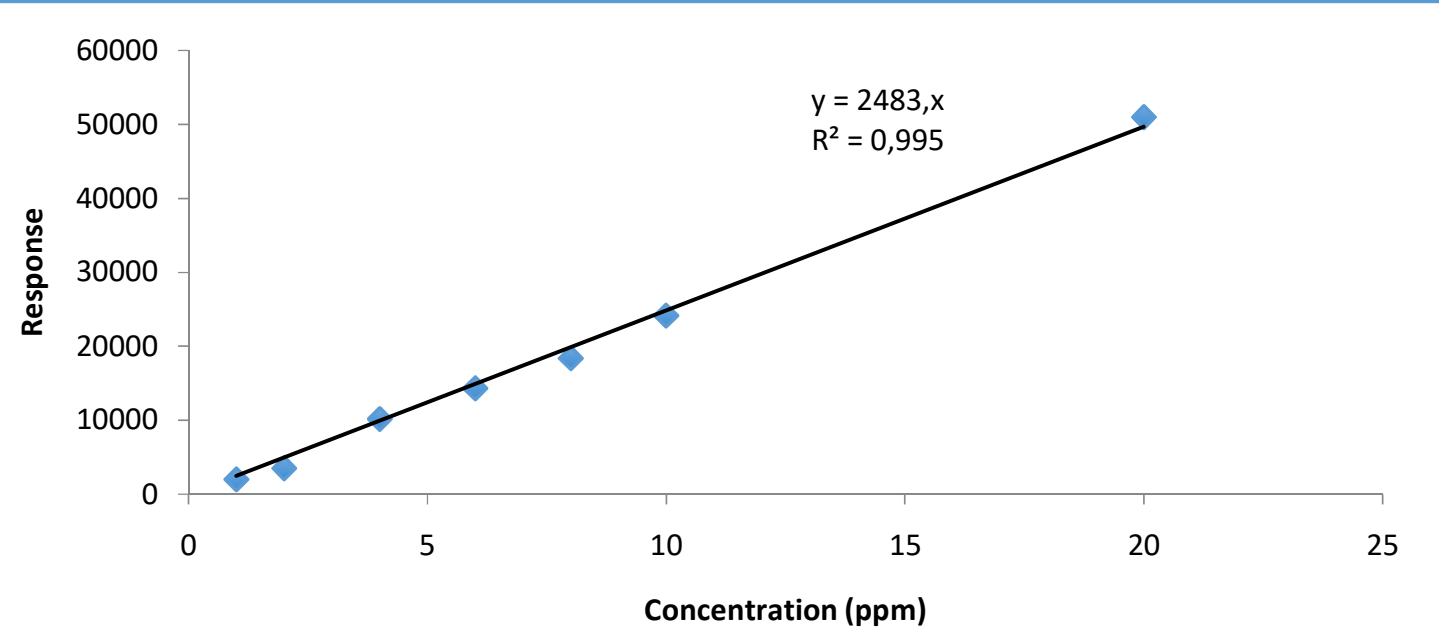

Fig.2.Anthracene calibration curve

\subsection{SPE and LLE Extraction Method Analysis}

Fig. 3 shows the average anthracene recovery percentage using SPE and LLE methods. The average recovery for SPE and LLE were 46.22\%and 96.65\%respectively. ANOVA showed that there was a significant difference between SPE and LLE with $p<0.05$ as in Table 1 . This ANONA result was also verified by the significant different result in t-test where $p<0.05$ (Table 2). Overall, the LLE method proved to be more effective compared to SPE methodwith a higher recoveryin difference of $54.43 \%$.

The LLE method showed better recovery than SPE method. This may be due to SPE having a very low selectivity because of its sorbents or stationary phase[11]. Furthermore, SPE also known in excellent performance for wide range of compounds extraction. In the case of needing narrow range of compounds to be detected in this study for anthracene extraction, LLE has performed its advantages.

For extracting PAH of acenaphthene in milk product, LLE methodology had successfully extracted acenaphthene but not with SPE method[12]. In [13] reported that extraction of their targeted compounds including anthracene showed a recovery range of $70-120 \%$ for SPE and LLE, which also supports our findings.

In this study, the maximum extraction of anthracene is crucial. LLE method is chosen to proceed with the method development in next section. This is due to high and significant difference of average recovery for SPE and LLE. Furthermore, LLE method offers advantages of cost effectiveness, more environmentally friendly with use of solvents that are less toxic 
and has minimum specific instrument requirement [11].

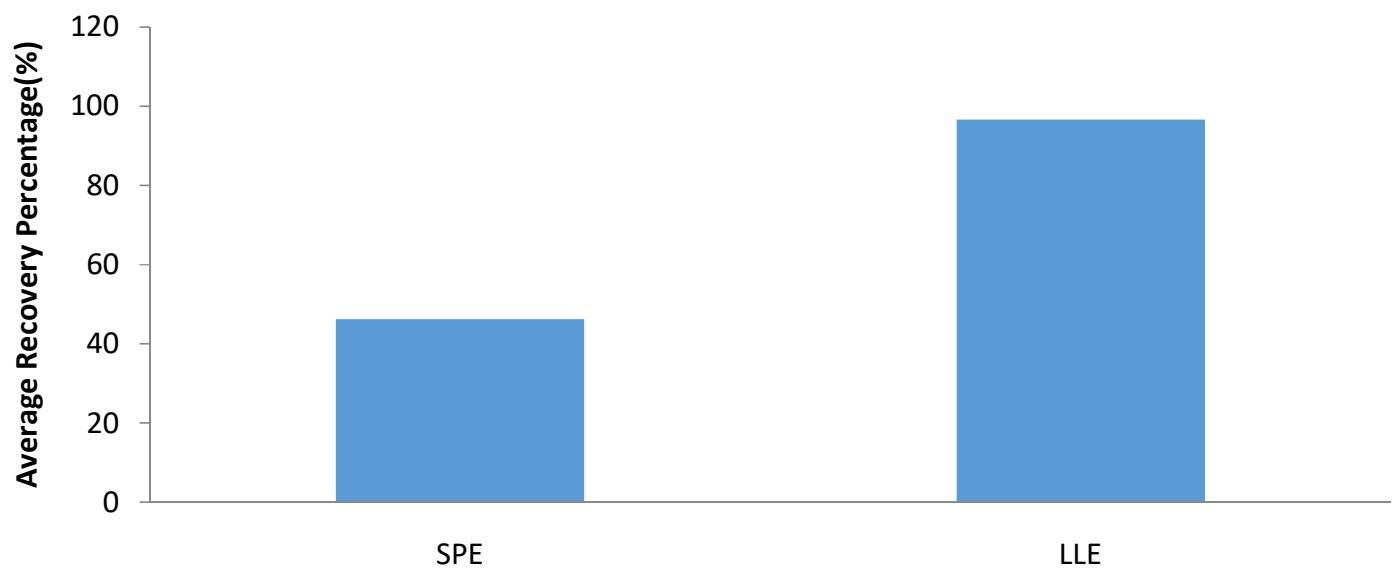

Fig.3.Anthracene recovery percentage of SPE and LLE methods

Table 1. One-way ANOVA for LLE and SPE of anthracene

\begin{tabular}{ccccccc}
\hline Source of Variation & SS & df & MS & F & P-value & F crit \\
\hline Between Groups & 5085.15 & 1 & 5085.15 & 8.44352 & 0.027129 & 5.987378 \\
Within Groups & 3613.529 & 6 & 602.2548 & & & \\
Total & 8698.679 & 7 & & & & \\
\hline
\end{tabular}

Table 2. Anthracene extraction using SPE and LLE t-test results

\begin{tabular}{ccc}
\hline & SPE & LLE \\
\hline Mean & 46.22342638 & 96.64738 \\
Variance & 177.7818558 & 1026.728 \\
Observations & 4 & 4 \\
Pearson Correlation & -0.390107703 & \\
Hypothesized Mean Difference & 0 & \\
df & 3 & \\
t Stat & -2.571639806 & \\
$\mathrm{P}(\mathrm{T}<=\mathrm{t})$ one-tail & 0.041187818 & \\
t Critical one-tail & 2.353363435 & \\
\hline
\end{tabular}

\subsection{Sonication Effect on Extraction Method Development}

Fig. 4 shows the average anthracene recovery percentage in three methods of development.

The average recovery for method 1, 2 and 3 were $94.25 \%, 65.06 \%$ and $73.67 \%$ respectively. Based on the average recovery, method 1 showed the highest average recovery. Table 3 shows not significant difference among the three methods in ANOVA analysis since $\mathrm{p}>0.05$.

The results showed that sonication prior to sample withdrawal in method 1 helped in recovering anthracene from the sample matrix because anthracene has particles in MSS 
solution that it can adhere to.In addition, sonication caused light and more water soluble PAHs to be released in the supernatant[14]. However, sonication during extraction in method 2 with methanol and acetonitrile caused a decrease in recovery. This may be due to degradation of compound during sonication and hence lower extraction efficiency was observed. In [9]supported our findings where sonication was reported less efficient than Soxhlet extraction, especially for lower molecular weight PAHs.Lower extraction efficiency in method 3 mechanical agitation caused by shaking than sonication was recorded. This may be due to less contact of anthracene with sample matrix compared to sonication. Mechanical agitation was less used compared to sonication due to lower extraction efficiency, larger results variation and less selective[9]. Hence, method 1 is chosen as method of extraction among the three as it represents the optimum recovery percentage.

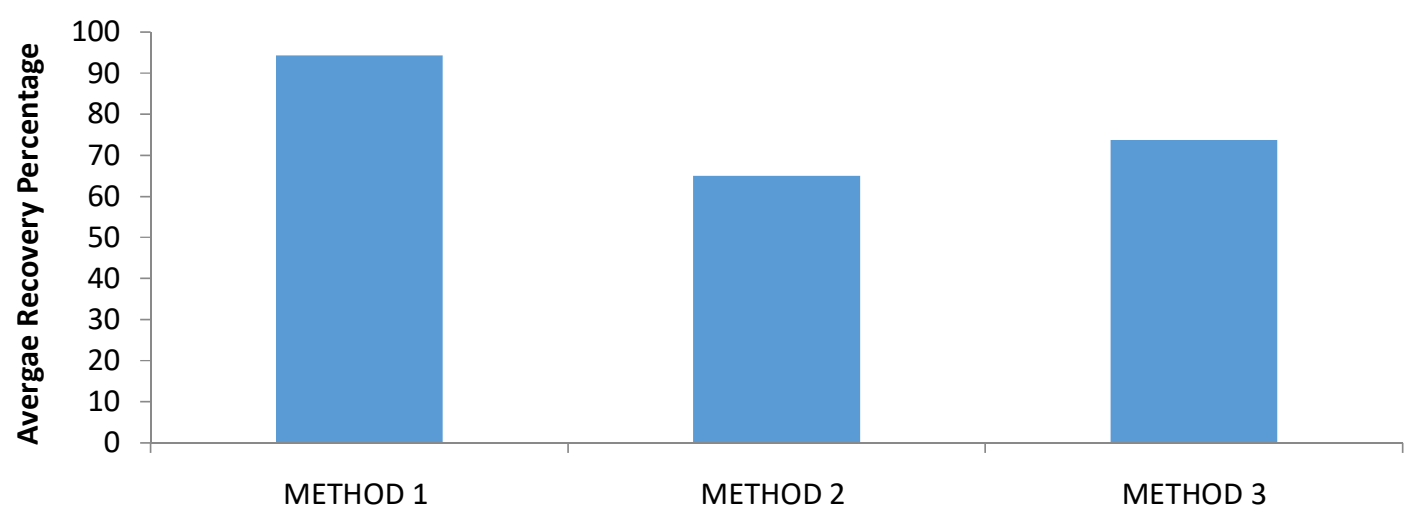

Fig.4.Anthracene recovery percentage for method development

Table 3. One-way ANOVA on method development for anthracene extraction

\begin{tabular}{ccccccc}
\hline Source of Variation & SS & df & MS & F & P-value & F crit \\
\hline Between Groups & 900.113541 & 2 & 450.0568 & 0.308369 & 0.755451 & 9.552094 \\
Within Groups & 4378.43126 & 3 & 1459.477 & & & \\
Total & 5278.5448 & 5 & & & & \\
\hline
\end{tabular}

\section{CONCLUSION}

LLE and SPE methods were evaluated as potential efficient extraction methods for anthracene in this study. The LLE method resulted in the highest average recovery percentage, which was $96.65 \%$ as compared to SPE method of $46.22 \%$. The one-way ANOVA and t-test show significant differencefor SPE and LEE methods. Meanwhile, sonication prior to sampling 
recorded $94.25 \%$ of anthracene recovery before proceeding to LLE. Other methods of mechanical shaking and sonication extraction were less effective. Thus, the development of efficient extraction method andanalysis of anthracene are useful forfurther anthracene degradation study and PAHs degradation pathways evaluation.

\section{ACKNOWLEDGEMENTS}

This work was supported by the MOHE under grant 600-RMI/FRGS 5/3 (26/2015) and UniversitiTeknologi MARA (UiTM) facility support.

\section{REFERENCES}

[1]Ali MIA, El-ghany MNA, Khalil N M. Biodegradation of some polycyclic aromatic hydrocarbons by Aspergillus terreus. African Journal of Microbiology Research, 2012, 6(16):3783-3790

[2]Grimmett P E, Lam YW, Porollo A, Syed K, Yadav JS. CYP63A2, a catalytically versatile fungal P450 monooxygenase capable of oxidizing higher-molecular-weight polycyclic aromatic hydrocarbons, alkylphenols, and alkanes. Applied Environmental Microbiology, 2013, 79(8):2692-2702

[3]Das P, Mukherjee S, Sen R. Improved bioavailability and biodegradation of a model polyaromatic hydrocarbon by a biosurfactant producing bacterium of marine origin. Chemosphere, 2008, 72(9):1229-1234

[4]Bohatier J, Bonnet JL, Dusser M, Guiraud Ã P, Kadri M, Laffosse J, Steiman R. Assessment of anthracene toxicity toward environmental eukaryotic microorganisms: Tetrahymena pyriformis and selected micromycetes. Ecotoxicology and Environmental Safety, 2005, 60:87-100

[5]Chen B, Hu D, Wang Y. Biosorption and biodegradation of polycyclic aromatic hydrocarbons in aqueous solutions by a consortium of white-rot fungi. Journal of Hazardous Material, 2010, 179(1-3):845-851

[6]Gao Y, Goikavi C, Kang F, Ling W, Waigi M G. Phenanthrene biodegradation by Sphingomonads and its application in the contaminated soils and sediments: A review. International Biodeterioration and Biodegradation, 2015, 104:333-349 
[7]Cheng Q, Feng Y Z, Li X Z, Lin X G, Liu W W, Wu Y C. Influencing factors and product toxicity of anthracene oxidation by fungal laccase. Pedosphere, 2014, 24(3):359-366

[8]Doerge DR, Freema J P , Moody J D. Degradation of Phenanthrene and anthracene by cell suspensions of mycobacterium sp . strain PYR-1. Applied and Environmental Microbiology, 2001, 67(4):1476-1483

[9]Gan S, Lau E V, Ng HK. Extraction techniques for polycyclic aromatic hydrocarbons in soils. International Journal of Analytical Chemistry, 2010, 2010:1-9

[10]Abualhasan M, Jaradat N, Mousa A, Zaid A N. Gas Chromatographic method validation for the analysis of menthol in suppository pharmaceutical dosage form. International Journal of Analytical Chemistry, 2017, 2017:1-5

[11]Andrade-Eiroa A, Canle M, Cerdà V, Leroy-Cancellieri V. Solid-phase extraction of organic compounds: A critical review. Part ii. Trends in Analytical Chemistry, 2016, $80: 655-667$

[12]Chen MF, Chung T L, Liao C J. Comparison of liquid-liquid extraction and solid-phase extraction for the determination of polycyclic aromatic hydrocarbons in the milk of Taiwan. Journal of the Taiwan Institute of Chemical Engineers, 2010, 41(2):178-183

[13]Antonio M D, Bienvenida G L, José R M, Juan F G R.Comparative evaluation of liquid-liquid extraction, solid-phase extraction and solid-phase microextraction for the gas chromatography-mass spectrometry determination of multiclass priority organic contaminants in wastewater. Talanta, 2013, 117:382-391

[14]Choi S D, Kwon H O, Lee S E, Oh J Y. Leaching of polycyclic aromatic hydrocarbons (PAHs) from industrial wastewater sludge by ultrasonic treatment. Ultrasonics Sonochemistry, 2016, 33:61-66

\section{How to cite this article:}

Abidin A N Z, Talib S A, Alias S, Tay C C. Effective and reliable method for extractions of anthracene. J. Fundam. Appl. Sci., 2017, 9(5S), 695-705. 